of the shortage remains the inappropriate attitude of hospital medical staff.

While a regionally based information and education scheme as described by Dr Knapp has undoubtedly improved the yield of kidneys for donation, the shortfall will not be fully corrected until hospitals introduce an admissions policy whereby comatose patients with severe head injury or spontaneous subarachnoid haemorrhage are automatically admitted to an intensive therapy unit. This will confer two benefits: the prompt initiation of mechanical ventilation should the patient's condition deteriorate; and better care for the survivors. Such an admissions policy has existed at our hospital for several years and has served to improve the yield of kidneys for donation.

\section{A Luksza}

Whiston Hospital,

Prescot,

side L35 5DR

${ }^{1}$ Luksza AR. Br Med f 1979 ;i:1316-9.

\section{Will breast self-examination save lives?}

SIR,-Concern about the high incidence of and mortality from breast cancer in Britain has in recent years directed attention to methods of early detection. Reports on the preliminary results of screening programmes and health education campaigns are encouraging. ${ }^{1}$ To the best of our knowledge, these programmes are aimed solely at women; yet one preliminary finding in our current research on men's attitudes to breast cancer and mastectomy indicates that it is probably important to focus these campaigns on men as well as women.

The exploratory stage of this study involved interviewing men whose wives had been admitted to hospital for the excision of a benign breast lump. We used a semistructured questionnaire and interviewed 25 men aged between 30 and 62 years. Owing to the small numbers interviewed we would like to stress that results are highly tentative. One striking finding, however, has emerged; without being asked, 20 of the interviewees suggested that they had played a major role in helping their wife to come to a decision to seek medical advice. Moreover, most considered that they had a positive role to play in encouraging their wife to practice breast self-examination and felt they would have liked more information about this, but were unsure where to obtain it.

These preliminary results suggest that health education policy-in the breast cancer field at least-must be aimed as much at partners as at the unfortunate host of this disease. It is encouraging that this conclusion seems in line with the results of the only comparable study we were able to find, undertaken by Wellisch and colleagues in California. ${ }^{2}$ This study assessed the factors related to a man's adjustment to mastectomy 22 months following his wife's operation. Data were collected from 29 men and indicated certain focal points in the process of adjustment; one of these pointed to the man's involvement in the decision-making process to seek medical treatment.

In the later stages of our project, we will explore the role of men whose wives have had mastectomy, interviewing approximately 50 subjects and investigating in more detail their involvement in the diagnostic, treatment, and adjustment processes. Because about onequarter of breast cancer patients present with inoperable tumours, as stated in your leading article by Professor Michael Baum (16
January, p 142), despite early detection programmes, the long-term objective of our study will be to formulate an effective programme that does not neglect the role the male might play in encouraging his partner to participate in available breast cancer detection programmes and, in particular, to seek early medical advice on discovery of any breast problem.

\section{LORRAINE TAYLOR}

ALEX KaLACHE

Department of Community

Medicine and General Practice

Radcliffe Infirmary, Oxford OX2 6HE

UK Trial of Early Detection of Breast Cancer Group. Brf Cancer 1981;44:618-27
Wellisch DK, Jamison KR

Psychiatry 1978;135:543-6. Pasnau RO. Am $f$

\section{How effective are our child health clinics?}

SIR,-From both personal and published communications (13 March, p 819) it is clear that my article on child health clinics (20 February, p 575) has touched on a sensitive issue. There are some points arising from it that I would like the opportunity to put on record, and I hope they will clarify my motives.

I recognise that this study was small and represents one doctor's experience in one clinic, but if these findings are not typical and the questions that these findings pose are not justified then others must publish their experience. I share the sentiment of those who feel we should take a broader look at the role of child health clinics. The fact is, however, that developmental screening and child health surveillance form nationwide the bulk of the clinic doctor's work-a fact that cannot be escaped, whatever view of child health clinics I or others choose. Providing a preschool screening service has virtually become a health authority obligation. The review body is considering paying GP's for doing the work. If screening is unimportant (as some suggest), why are we debating paying GP's for four examinations a child in the preschool years? All of us are aware that significant and often serious handicap repeatedly goes undetected. We are also being made increasingly aware of the many other social, emotional, and health needs of young children that are not catered for. Our present strategies have been inadequately evaluated. We must not be afraid to look critically and with unbiased minds at what we are doing in the community. Unless we do so we will remain entrenched in practices which are only laid down as guidelines. Guidelines that are based almost entirely on opinions, expert opinions that we must respect, but no one's opinion is above critical examination, especially when it carries enormous implications for the allocation of time and resources. We have a duty to produce the evidence that will enable doctors who want to work in the community to believe in their role. If we do not then we cannot expect their job to be done well or done at all. We need a positive and radical response to the needs of our children, and if there are things we are doing that are unproductive we must know about them. We could then abandon unproductive practices and focus our professional skills on the many other areas of need.

Finally, I would like to clarify two specific points raised in correspondence. Although the article described two periods six months apart, I worked in the clinic for two consecutive years (1979-80). During this time I was one of three paediatricians who covered the clinic.
Two of us were members of the same department, and communication and continuity of care were excellent. Secondly, the majority of the population we served was by any standards socially deprived. The small number of "social and emotional problems" I identified must be seen within this context. These six families were those in whom problems were acute and required immediate action. For example, a homeless teenage single parent with a small baby, or a mother with puerperal depression whom I saw in an acute state of agitation and anxiety. The latter was employed as a hospital cleaner and had seen the partially dissected body of a baby the same age as her own.

W A HENDRICKSE

Department of Child Health, Nottingham NG7 2UH

\section{Do patients cash prescriptions?}

SIR,-I was interested to read Dr J A C Winter's comments (13 March, $p$ 827) on Mr Aly Rashid's article entitled "Do patients cash prescriptions ?” (2 January, p 28). Mr Rashid's figure of nearly $20 \%$ of prescriptions being uncashed should be treated with caution, partly because of the small size of his sample and partly because there may, indeed, be wide variations in compliance rates as Dr Winter suggests.

Our findings reported in $1976^{1}$ were that $7 \%$ (113 out of 1611 ) of prescriptions issued by a general practitioner and his trainee in a mining area practice during a period of one month (November 1974) were not cashed. The people least likely to cash their prescriptions were men aged 25-34 years, particularly those who were coal miners. The comment was made at the time that to get sickness benefit these men have to consult a doctor, but the medical content of the consultation in these circumstances is often perceived by them as irrelevant and the medication is rejected. On the other hand, prescriptions for children and old people were nearly always cashed. We noted also that the percentage of uncashed prescriptions for the trainee was higher than for the trainer, but age could have been a factor since older patients tended to consult the established doctor whom they knew. It is obvious that many factors are at play, and Dr Winter is correct to emphasise the need for further studies. I would like to add a plea that future studies collect sufficiently large samples of data to analyse these factors properly.

JoHN E LUNN

Department of Community Medicine,

Sheffield University Medical School,

Sheffield S10 2RX Waters WHR, Gould NV, Lunn JEL. Br Med $\mathcal{f}$
1976;i:1062-3.

\section{Women in general practice}

SIR,-Thank goodness for Dr Julia Lowe's letter (20 March, p 904). It is rare to read a letter in the $B M f$ which mentions common sense. I wonder what the Secretary of the BMA would have to say about my case-no doubt something equally condescending.

I have worked full-time and part-time in community health since 1969 . I entered it as a career compatible with having children and got the Diploma in Child Health before I 